\title{
A importância da língua grega
}

\author{
Nilsa Areán-García
}

Resumo: This article explains the history of the Greek language, showing its influences, the geography of Greece that changed several times, many years ago, because the wars. The importance of the Greek language during the last centuries for other languages, like the Turkish Ottomans.

Palavras-chave: História da Grécia e da lingua grega, influências da língua grega, geografia da Grécia antiga;

A língua grega faz parte da família das línguas indo-européias, ainda que em seu léxico haja empréstimos que notadamente não sejam do indo-europeu. Pode-se seguir o desenvolvimento da língua grega durante um longo período: desde os primeiros traços em sua época micênica até o grego moderno, o que fornece um percurso de mais de três mil anos de uma história política e cultural, nos quais se manteve uma língua viva, que se desenvolveu até os dias de hoje, e ainda segue sua jornada de desenvolvimento.

De acordo com Buck (1952:15-16), os primeiros gregos chegaram à península helênica pelo norte, por volta de 2.000 a.C. e lá se estabeleceram, bem como em suas ilhas. Entretanto, dos povos anteriores, conhecidos pelo nome de pelasgos, pouco se sabe, ainda que seus falares devam ter influenciado traços do

Nilsa Areán-García é doutoranda em Filologia Românica, FFLCH-USP, sob orientação do Prof. Dr. Mário Eduardo Viaro.

Organon, Porto Alegre, $\mathrm{n}^{\circ} 44 / 45$, janeiro-dezembro, 2008, p. 141-149 
grande influência na cultura grega. Entretanto a épica homérica e a primeira prosa grega foram escritas em jônico.

Houve, então, uma divisão geográfica dialetal devida à distribuição dos poSabe-se que antes da invasão da Península Balcânica, os povos que mais te gregos, situavam-se ao norte desta, onde tiveram tarde foram chám depois da ocupacontato com várias línguas indo contato com povos de línguas similares e de fron(5,3,1) apud Buck $(1952.16)$, era çários e trácios, que segundo HERODOTO $(5,3,1)$ aptud BUCK (1952:

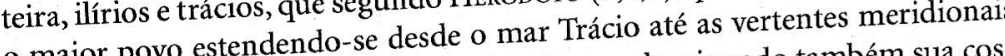
- Á Menor dominando também sua cosdos Cárpatos e dali emigraram até a Ásia Menor dominando também sua costa conforme o ilustrado no Mapa 1.1. Acredita-se que mais intensa tenha sido influência dos povos que pertenciam ao grupo hitito-luvita do indo-europeu na formação da língua grega, pois na Ásia Menor, com os avanços dácios, cilícios ção "grega" houve um contato cada vez maior com os lídios, cáro ou hitito-luvita, e paflagões, todos pertencentes ao grupo lingüístico anatólic

conforme Hofmann, DebrunNer \& SCHERER (1986: 32-35). XV a XII a.C., feitas

Escritas em grego estão as tábuas micênicas dos sectúico-micênicos como em argila, que documentam os arquivos de palácios minoico-miadores. Segundo o Cnossos e que detêm grande interesse de lingüistas e historiador-se o alfabeto MeILeT (1930: 16-51), no século VIII a.C, introduziu-se e adotou-seo alfato de origem fenícia. Na mesma época, a literatura grega começou com os pomo da atribuídos a Homero, que foi um grande marco, não somente grego comoresa Ilíada a Odisséia. Desde então, as f são na cultura grega foram sendo definidas: áficos, o teatro, especialhistoriográfica, a oratória, a filosofia e os tratados cienticos, o tea gree usad mente as formas clássicas: tragédia e comédia. Entretanto, a lingua grega uada na escrita é complexa, pois houve uma grande variedade dialetal depois que os regos se enaração de (1954:4-8), podem ser sua língua das demais indo-eur grupos dialetais do grego: jônico-ático, eólio, distinguidos quatro grandes grupos dialetais do grego: jônico-ático, eólô cóngloba também o grego do nor pralmente agrupados na categoria chamada grego aqueu. $O$ 作 作 Ática; o eólio na Tessália, Beócia, na ilha de Lesbos e no litoral da Asia Meno ilha de Chipre dórico partoponeso, nas ilhas colonizadas pelos Como em muitas regiôes do Sul da dórios: Creta, Rodes, Cós, Terá e outras, bem como do noroeste era falado na região mais próxima ao mar Adriático, no Epicuro e zonas proximas. Para Mético dos (1930: 73-109), o que é chamado de grego clássico é, em geral, géricles, de (1V a ceja, o que se usava em Atenas da época de Péricles, séculos V e IV a.C., ou seja, o que se usava em Ate ática teve um predomínio soPlatão e dos oradores e dramaturgos. A variante ática cultura helênica, como a cidade da democracia, do teatro e da filosofia, durante a sua hegemonia porcer ca. Mesmo depois de perder importância política, Atenas continuou a exercer Entretanto, também houve a utilização das variantes de acordo com as convenções literárias, que impuseram aos vários gêneros uma ou outra forma. Por exemplo, Hesíodo era da Beócia, mas compôs os seus poemas em jônico. Píndaro, também da Beócia, compôs suas odes em dórico. Apesar das diferenças dialetais, a língua grega permitia a relação entre uns e outros gregos, mas, os dialetos a cabaram desaparecendo com a extensão do uso do grego no âmbito comercial e como veículo cultural e de expansão do Império. Essa língua comum grega, ou koiné, que havia sido formada sobre o ático, mas com características do jônico e dórico, se consolidou como uma língua franca, de acordo com PISANI (1954: 46-70)

Sabe-se que na Antigüidade houve um período de auge helenístico com a expansão da cultura helênica e da koiné grega como língua franca, em todo o imenso domínio nas costas mediterrâneas, conforme o Mapa 1.3: no norte da África, Egito (como língua oficial) e no Oriente Médio até as fronteiras da Índia, por meio das guerras de conquistas e colonizações, promovidas em sua maior parte por Alexandre, o Grande, no final do século IV a.C. e administradas, logo depois, por seus sucessores. A criação da biblioteca de Alexandria é apenas um exemplo da grande influência exercida pela cultura dos conquistadores. Ainda que o Império Alexandrino tenha sido fragmentado, a influência do grego como cultura e língua manteve-se por muito tempo nessas regiões e pode ser considerada a maior das conquistas de Alexandre, o Grande.

É interessante notar, que durante a colonização romana no Oriente Médio, o grego permaneceu ainda como língua franca, identificando seu poder de assimilação pelos povos que ali habitavam, já que, segundo BASSETTo $(2001,89)$ : "no Oriente a latinização foi bastante superficial". Assim se explica que os livros sagrados judaicos tenham sido escritos em aramaico e hebraico, enquanto o Novo Testamento (evangelhos, cartas dos apóstolos e apocalipse), pregado pelos cristãos, tenha sido escrito na koiné grega, e não em latim. Dessa forma, a expansão do cristianismo, juntamente com a expansão do Império Romano, como pode ser visto no Mapa 1.4, principalmente após Constantino, levou a uma forte retomada de termos do grego com o uso da bíblia mesmo depois de sua tradução para o latim. Esses termos gregos foram mantidos pela Igreja $\mathrm{Ca}$ tólica até hoje por meio do latim eclesiástico.

A koiné grega também era a língua que os filósofos, mercadores e governantes do Oriente utilizavam durante o Império Romano. Mesmo os romanos escreviam em koiné na zona oriental do Império. Em Roma, estudava-se o grego nas famílias patrícias, pois era a língua da filosofia e ciência. É curioso notar que o Imperador Romano Marco Aurélio escreveu os seus Solilóquios em grego, pois era uma língua de grande prestígio, mesmo no Império Romano do Ocidente. 
tos levados pelos sábios que fugiram de Bizâncio com a ocupação turco-otomana.

Entretanto, não só a religião e a fraca latinização do Oriente foram os resEntre diversos fatores, como ponsáveis pela importância da cultura grega. por exemplo, que muitos dos escravos feitos pelos rom no latim. A cultura grecultos ajudaram nessa disseminação de termos gregos no latim. A cultura grecultos, ajudaram no poesia, mitologia, ga aparece em todos os campos da civilizça romana também houve grande oratória, escultura e arquitetura. Na filosofia discípulos das escolas filosóficas influência das idéias filosóficas gregas, com discipulos icos romanos mai cestóicos, pitagóricos, platonicos. Os romanos mais gregas: cínicos, epicuria destacados sempre viajavam à Grecia para helênicas continuando-as em verregos, como também, estudavam as artes helenicas contina ando-as e sintática (án própria língua latina possui uma estrutura gramatical e sintática sôes latinas. A própria lingua la corma, os romanos souberam absorver muito similar à grega. Então, de certa forma formação de seu Império, por isso adaptar grande parte da cultura helênica na formaça de seu Império, por isso a telativo à cultura. Apesar de não se usar o mesmo termo o termo greco-latino, relative ám um determinado grau de absorção e adap tação do grego no latim.

Ampério Romano para

Desde que Constantino mudou a capital do Império Romano pan 1453, Constantinopla, em 330, até a conquista desta pelos turcos-otoma capital. Depois centro do poder político e cultural helênico passou a Império Romano com a de Teodósio, quando deixou de ser o centro de todo o Imperio Rompério Oriendivisão (como está ilustrado no Mapa 1.5), para Bizâncio ou Istambul, continuou tal, a cidade de Constantino, Constantinopla, Bizancio depois da queda de Roma arande influência helênica na região. Ainda depois da queda de Roma a exercer grande influencia há 476 (como está ilustrado no Mapa 1.6), e do Império Romano do Ocidente em 476 (comose mil anos, mesmo que suas o Império do Oriente ainda perdurou por quase mil anos ocidental tenham fronteiras tenham sido reduzidas, suas relações com do irradiação do grego, sido dificultadas e a Igreja Católica, uma das

tenha sido dividida em Romana e Ortodoxa.

Também o Império Árabe foi transmissor de parte do legado helén, álgebra, meio de suas versões nos livros de medicina, astron "Guerra Santa", ainda que ciências, e mesmo em meio à sua expansão com a "Guerra Santa", aine mostraciencias, emén mário Bizantino, conforme mostracom menores proporções foi mantido o lmperaticamente esquecido no Ocidente do no Mapa 1.7. Contudo, o grego foi praticamente nenascimento, após a tomada de durante a Idade Média e só retomado

Constantinopla pelos turcos-otomanos.

Constantinopla, em 1204, foi alvo das Cruzadas, or a continuou como cenara combater a "Guerra Santa" dos islâmicos, mas ainda continulmente, os textos para comban convava a tradição e, principalmente, os textos tro de uma civilizçán qússica. Após a queda de Constantinopla, tomada pelos gregos da Antigüidade Classica. A turcos, estes textos chegaram á XIV e XV d.C., devido às traducões e Renascimento. Na Europa dos séculos Xivide Clássica, sobretudo na Península estudos dos textos gregos da Antigüidade Classicentista, a partir dos manuscriItálica, nasceu o movimento Humanista Renascentista, a partir dos
Entretanto, durante muitos séculos o Ocidente ignorou o grego, enquanto no Oriente se manteve como língua do mundo bizantino.

Depois que os turcos tomaram o poder político e instauraram sua língua em seu domínio, conforme o Mapa 1.8, os gregos continuaram falando sua língua em uma região pobre na antiga Hélade. Somente no século XIX, o grego voltou a ser a língua oficial de uma nova nação, a nova Grécia. O novo grego pode ser considerado uma continuação da koiné que perdurou e também se modificou durante o período de língua franca do Império Alexandrino e do Império do Oriente.

Assim, o Humanismo recuperou no Ocidente a cultura helênica que culminou na corrida pelo saber, nas Universidades e na base para a tecnologia dos últimos séculos. Nesse afã de estudar o panorama do grego começaram os estudos de Filologia Clássica, com ensino da língua grega em centros de excelência, analisando os termos gregos, introduzidos através do latim, e declarando o quanto, segundo LÓPEZ-EIRE (2003), é imprescindível conhecer o grego para conhecer os aspectos culturais e atuais das línguas românicas.

Segundo PIEL (1989: 14), a influência do grego veiculado pelo latim foi muito mais intenso no período humanista e desde então continua até os dias de hoje com vasta importância na formação lexical "sendo porventura a língua portuguesa entre as românicas a que maior rendimento tirou e continua a tirar deste inesgotável manancial que são as línguas clássicas."

\section{Bibliografia}

BASSETTO, Bruno F. Elementos de filologia românica. São Paulo: Edusp, 2001. BUCK, Carl Darling. Comparative grammar of Greek and Latin. Chicago: The University Chicago Press, 1952.

HOFMANN, O.; DEBRUNNER, A. \& SCHERER, A. Historia de la lengua griega.( título original: Geschichte der griechischen Sprache; traductor al castellano: Sánchez Pacheco). Madri: Gredos, 1986.

LÓPEZ-EIRE, Antonio. Una ejemplar historia de la lengua: la historia de la lengua griega. In: La langue grecque et son histoire. Atenas: Centre de la Langue Grecque, 2003. 101-106.

MEILLET, A.. Aperçu d'une histoire de la langue grecque. Paris: Hachette, 1930. PIEL, J.M. Estudos de Lingüística Histórica Galego-Portuguesa. Lisboa: Imprensa Nacional-Casa da Moeda, 1989.

PISANI, Vittore. Breve historia de la lengua griega. Montevideo: Facultad de Humanidades y Ciencias - Universidad de la República, 1954

Organon, Porto Alegre, n 44/45,janeiro-dezembro, 2008, p. 141-149 


\section{Anexos}

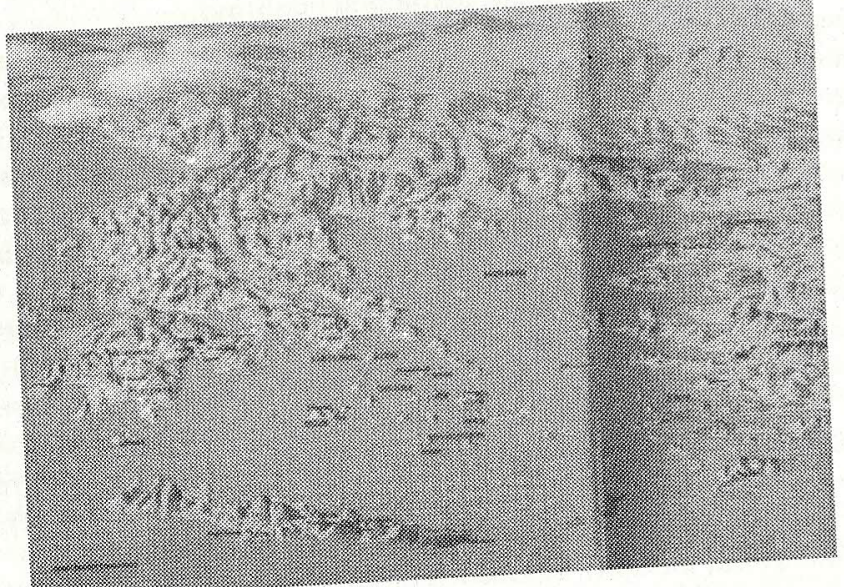

Mapa 1.1.Primeiras civilizaçōes gregas.

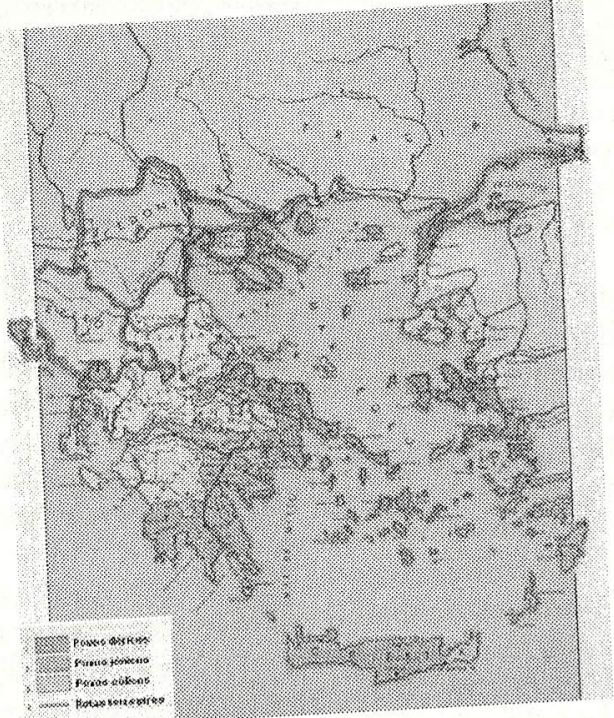

Mapa 1.2. Divisão política da Grécia Antiga.

-

Obs: a qualidade das imagens devem-se a qualidade dos arquivos envindos pea autora do arigoOrganon, Porto Alegre, $\mathrm{n}^{\mathrm{0}} 44 / 45$, janeiro-dezembro, 2008, p. 141-149

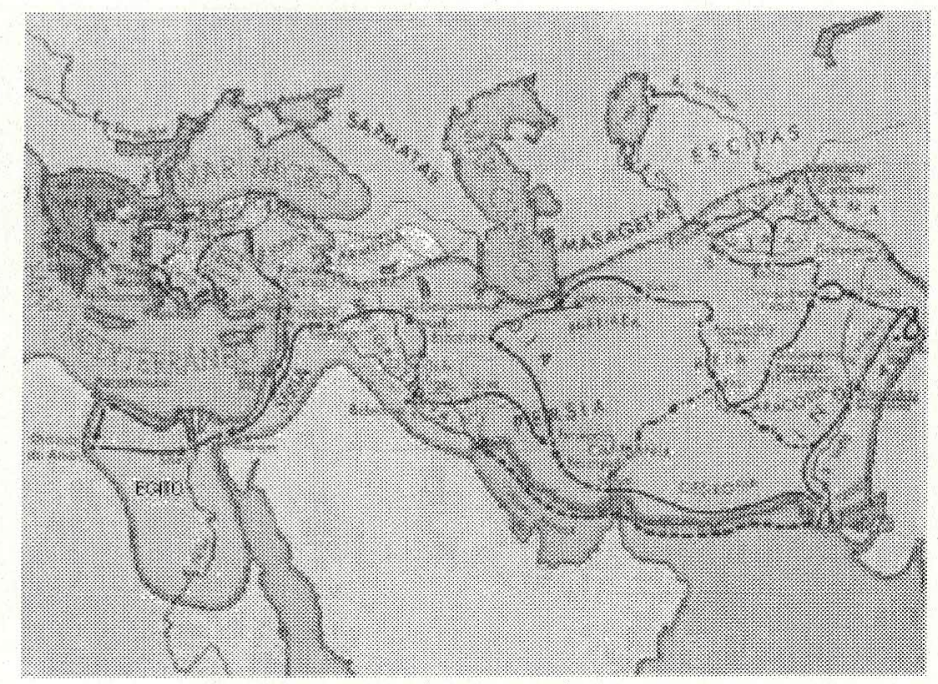

Mapa 1.3. O Império Alexandrino e suas principais rotas de expansão.

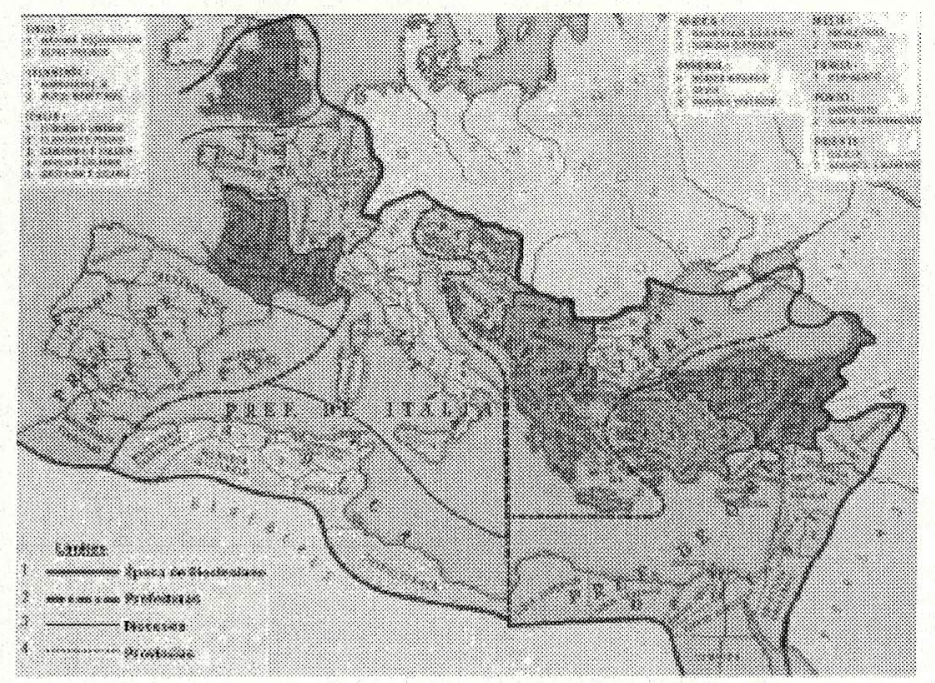

Mapa 1.4.0 Império Romano.

Organon, Porto Alegre, $n^{2}$ 44/45, janeiro-dezembro, 2008, p. 141-149 
Nilsa Areán-García

148

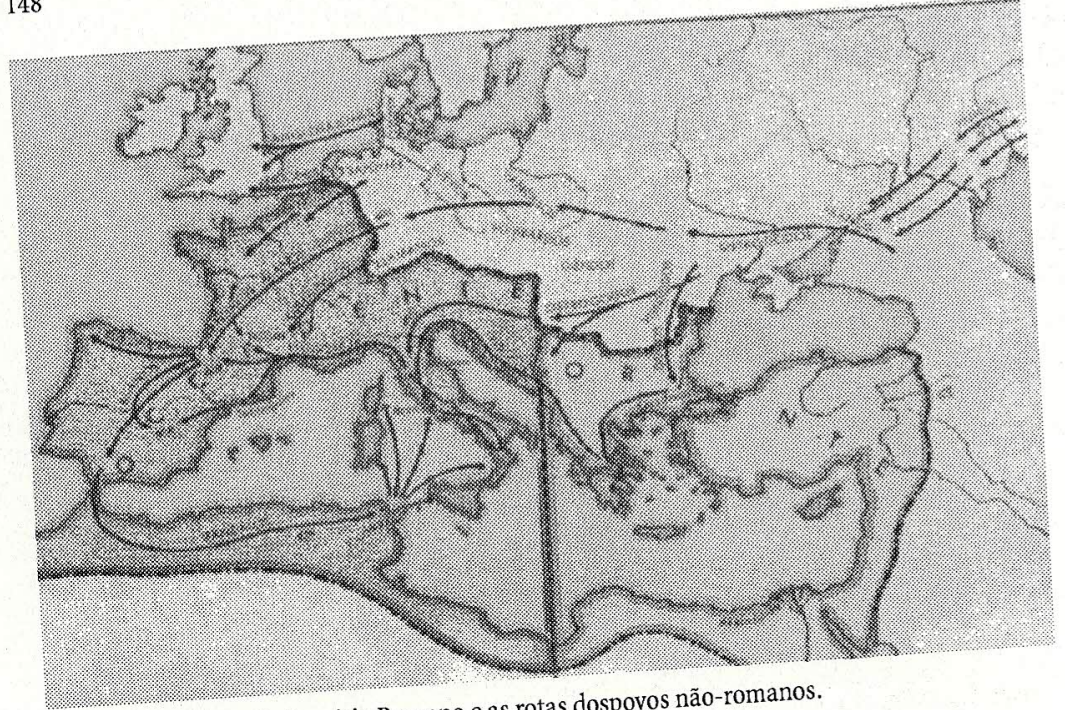

2.

Mapa 1.5. A divisão do Império

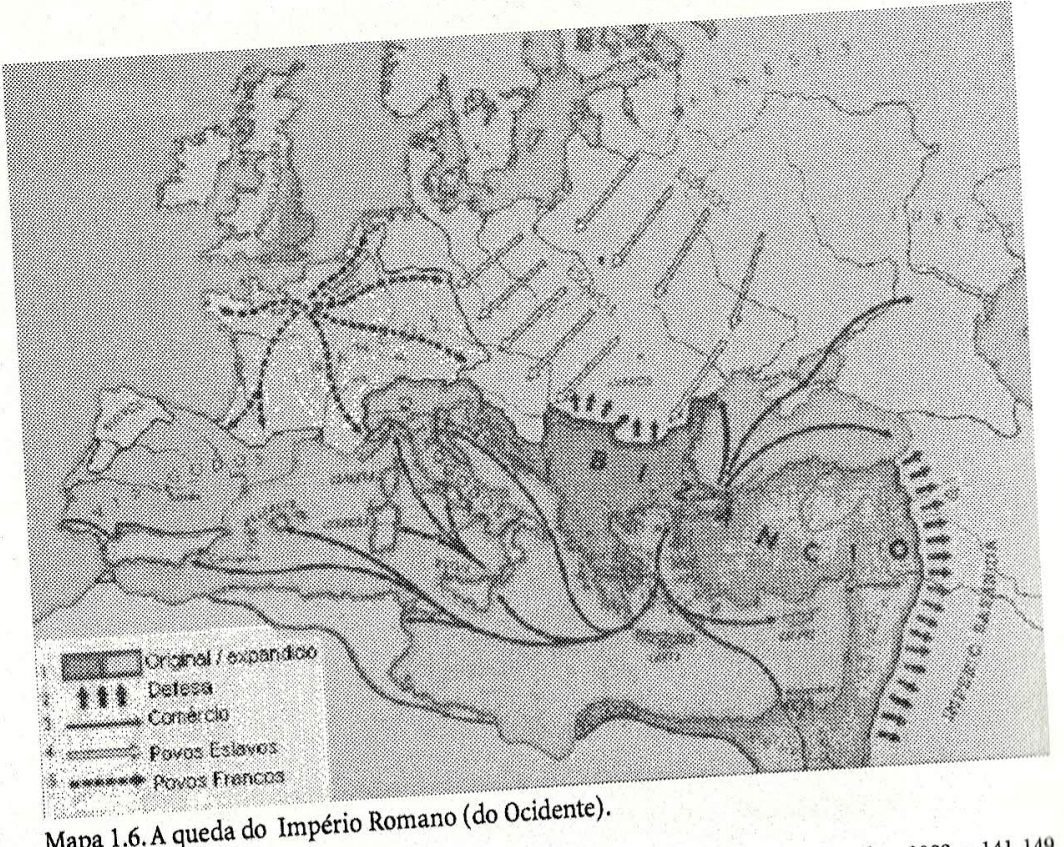

Parto Alegre, $\mathrm{n}^{2} 44 / 45$, janeiro-dezembro, 2008, p. 141-14
A importância da língua grega

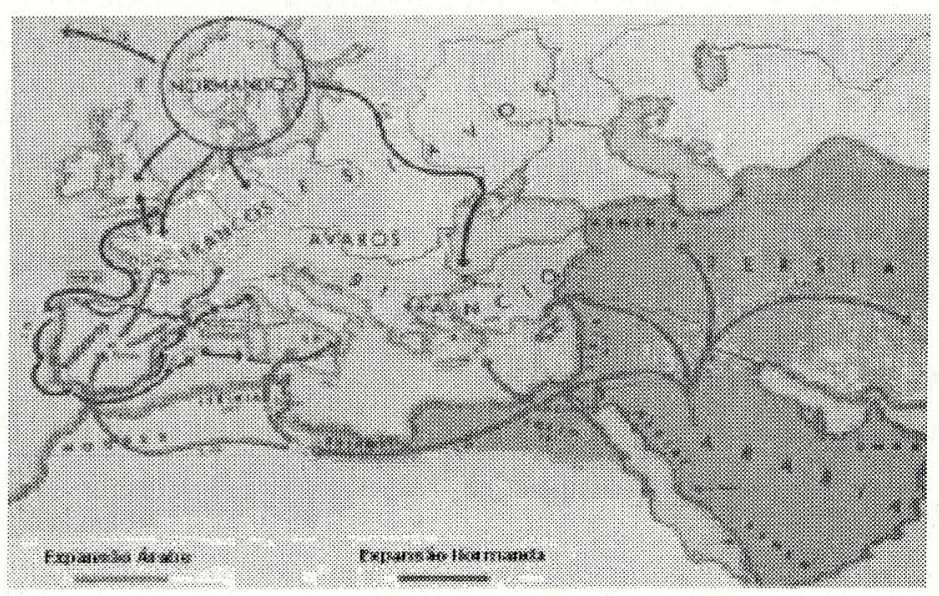

Mapa 1.7. A expansão do Império Árabe.

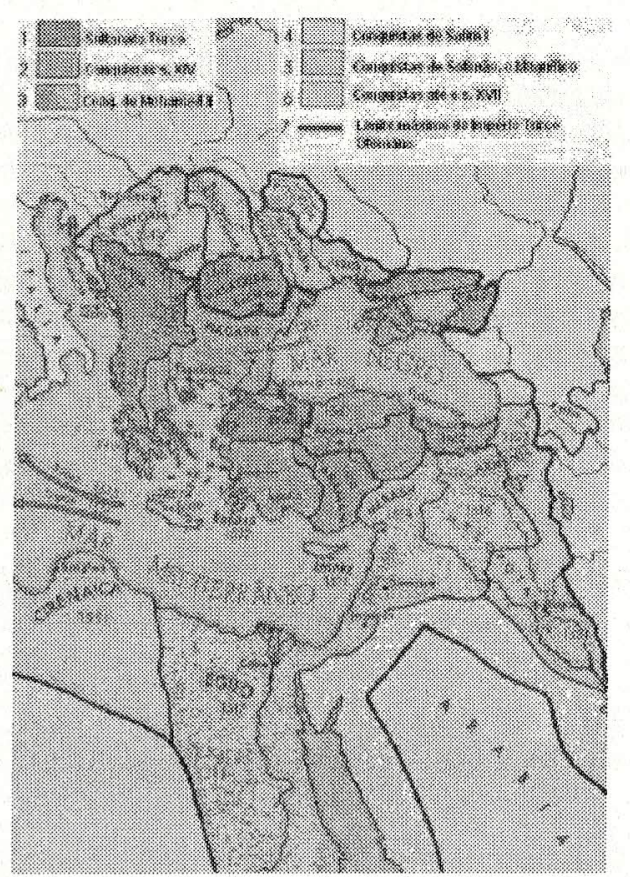

Mapa 1.7.A expansão do Império Turco.

Organon, Porto Alegre, n⿳o 44/45, janeiro-dezembro, 2008, p. 141-149 